\title{
Measuring Quality of Life in Type 2 Diabetic Patients at the Al-Wazarat Healthcare Center in Riyadh
}

\author{
Abdullah S. Albader ${ }^{1}$, Saleh Albahlei ${ }^{1}$, Mishary Almishary ${ }^{1}$ \\ 1. Family Medicine, Al-Wazarat Health Care Center, Riyadh, SAU
}

Corresponding author: Abdullah S. Albader, asbalbader@gmail.com

\section{Abstract \\ Background}

The prevalence of type 2 diabetes in the Saudi population is increasing at an alarming level. Diabetes is characterized by a considerable health and economic burden on the population and affected individuals.

\section{Objectives}

This study aims to assess the level of quality of life in type 2 diabetic patients and to investigate the determinant of quality of life in a primary health care setting.

\section{Methods}

The study used a cross-sectional design to investigate the quality of life among type 2 diabetic patients at the Al-Wazarat Health Care Center (WHC) in Riyadh, Saudi Arabia. The study used the Arabic version of the quality of life 36-items short-form questionnaire (SF-36).

\section{Results}

The study included 482 completed questionnaires out of the 525 distributed. The response rate is $91.8 \%$. The average age of the patients is $56.3 \pm 7.8$ years. The self-reported average body mass index (BMI) is $31.6 \pm 6.6$ $\mathrm{kg} / \mathrm{m} 2$. The duration of diabetes since diagnosis is $9.7 \pm 3.1$ years. The most common comorbidity was hypertension $75.9 \%$ (366/482). The multivariate regression analysis provided models that explained the role of certain variables in determining the quality of life in type 2 diabetic patients significantly. The most striking results are explaining the factors affecting physical functioning by $41 \%(\mathrm{R} 2=0.41)$ and mental health by $34 \%(\mathrm{R} 2=0.34)$.

\section{Conclusion}

Received 10/31/2019 Review began 12/19/2019 Review ended 12/21/2019 Published 12/27/2019

๑ Copyright 2019

Albader et al. This is an open access article distributed under the terms of the Creative Commons Attribution License CC-BY 3.0 , which permits unrestricted use, distribution, and reproduction in any medium, provided the original author and source are credited.
This study can influence the practices of medical practice and promotion in WHC specifically and Riyadh city more generally. The improvement and preservation of HRQoL in diabetic patients required an understanding of the factors that can influence it. The gender disparity is an area that needs further investigation. Changes in the delivery of healthcare in diabetes clinics to account for these factors may provide better results.

Categories: Family/General Practice

Keywords: determinants, qol, quantifying, diabetes, diabetic

\section{Introduction}

Diabetes is a growing problem globally with a great impact on societies and individuals at the health and economic levels [1-2]. Saudi Arabia is one of the most affected countries, with $21.7 \%$ of the estimated prevalence of type 2 diabetes mellitus [3]. Lifestyle restrictions and diabetes complications can have a considerable impact on the patient's quality of life (QoL) [4]. Due to the impact on the affected individuals, measuring these individuals' health-related quality of life (HRQoL) in Type 2 DM is important for a wide range of reasons, from diet and lifestyle restrictions to controlling symptoms, comorbidities, and treatments administration. All of these factors may lead to negatively affecting QoL. Additionally, it is one of the healthcare service objectives especially per diabetes guidelines to improve the patients' HRQoL [5-6].

The measuring tool was chosen after careful consideration of the literature. A review of the tools used to measure HRQoL in diabetic patients did not lead to the same results [7]. The authors concluded "No single measure can suit every purpose or application but when measures are selected inappropriately and data misinterpreted, any conclusions drawn are fundamentally flawed. If we value QoL as a therapeutic goal, we must ensure that the instruments we use are both valid and reliable.” [7]. Two systematic reviews showed that the most frequently used tools in HRQoL are the World Health Organization Quality of Life (WHOQOL) 
and SF-36 [7-8]. After consideration, we considered SF-36 as the tool for our study because of the readily validated Arabic version, the ease of administration, and the short time required to finish it [9]. The most comprehensive sources we found are two systematic reviews about the studies associated with sociodemographic and disease-specific variables [8-14]. Verna et al., in a 2017 study confirmed, using SF-36, several factors that influenced the HRQoL in 537 patients [15]. The investigation showed a negative association between depression symptoms, duration of diabetes, glycated hemoglobin (HbA1c) $>7 \%$, and micro- macrovascular complications with HRQoL. The study also reported that being male and physically active associate positively with HRQoL [15].

\section{Materials And Methods}

\section{Study area}

A cross-sectional study was conducted at the Al-Wazarat Health Centre (WHC). Type 2 diabetic patients with files and records for at least one visit and 18 years or older were included in the study. Type 2 diabetic patients who do not have records at the WHC and who are from outside Riyadh were excluded from the study.

\section{The research tool}

The research tool is the Arabic version of the QoL SF-36 by Rand corporation [9]. The SF-36 is a self-report, 36-item survey measuring the health-related quality-of-life. Thirty-five items are used to construct eight scales. An additional item measures health transition. The questionnaire included sociodemographic questions and medical history questions. The sociodemographic questions included age, gender, weight (self-reported), marital status, height (self-reported), education, and employment status.

\section{Statistical analysis}

The statistical analysis in this study consisted of two parts. The first part consists of the non-theoretical descriptive statistics and the second part consists of hypothesis testing. The hypothesis testing based on the assumption that the score of each domain in the questionnaire is a continuous, normally distributed variable. Each of the scores will be considered a dependent variable and will be regressed using ordinary least squares (OLS) regression against strings of independent variables. The 'best-fitting' model then will be selected using the information criterion (IC). There are two information criteria widely used for model selection. The first is Akieke's Information Criterion (AIC) and Bayesian Information Criterion (BIC). The idea of IC is choosing the model that gives the best explanation (R2) with the least complexity. Introducing variables to the regression model always improves the explanation of the model, but it also increases the complexity of the model with the newly added variables. AIC and BIC try to keep a trade-off between the amount of improvement and complexity added by the new variables. The 'best' model is the model that minimizes the IC. We will use AIC for our analysis, as it is more theoretically established.

\section{Results}

Table 1 describes the sample. The final sample size consisted of 482 completed questionnaires out of the 525 distributed. This accounts for a $91.8 \%$ response rate. The average age of the patients questioned was $56.3 \pm$ 7.8 years. The majority of the respondents were men $(63.1 \%(302 / 482))$. The participants were mostly married (80.7\% (389/482)). The education level of the participants was concentrated in secondary $(43.8 \%$ $(211 / 482)$ ) or elementary school ((149/482)). Unemployment represented the largest portion of $60.4 \%$ (291/482). The income category most reported was household income 3,001 - 6,000 SAR (36.9\% (178/482)). The self-reported average BMI was $31.6 \pm 6.6 \mathrm{~kg} / \mathrm{m}^{2}$. The duration of diabetes since diagnosis was $9.7 \pm 3.1$ years. 


\section{Cureus}

\begin{tabular}{|c|c|c|c|}
\hline Characteristic & Mean \pm SD & Frequency & Percentage \\
\hline Age (years) & $56.3 \pm 7.8$ & & \\
\hline \multicolumn{4}{|l|}{ Gender } \\
\hline Male & & 302 & 63.1 \\
\hline Female & & 180 & 36.9 \\
\hline Total & & 482 & 100.0 \\
\hline \multicolumn{4}{|l|}{ Marital Status } \\
\hline Unmarried (Single, Divorced, Widowed) & & 93 & 19.3 \\
\hline Married & & 389 & 80.7 \\
\hline Total & & 482 & 100.0 \\
\hline $\mathrm{BMI}^{\star \star}$ & $31.6 \pm 6.2$ & & \\
\hline \multicolumn{4}{|l|}{ Education } \\
\hline Illiterate/no formal education & & 86 & 17.8 \\
\hline Elementary & & 149 & 30.9 \\
\hline Secondary & & 211 & 43.8 \\
\hline College or higher & & 36 & 7.5 \\
\hline Total & & 482 & 100.0 \\
\hline \multicolumn{4}{|l|}{ Employment } \\
\hline Employed & & 191 & 39.6 \\
\hline Unemployed or retired & & 291 & 60.4 \\
\hline Total & & 482 & 100.0 \\
\hline \multicolumn{4}{|l|}{ Income (SAR) } \\
\hline$<3,000$ & & 104 & 21.6 \\
\hline $3,001-6,000$ & & 178 & 36.9 \\
\hline $6,001-9,000$ & & 96 & 19.9 \\
\hline $9,001-12,000$ & & 63 & 13.1 \\
\hline$>12,000$ & & 41 & 8.5 \\
\hline Total & & 482 & 100.0 \\
\hline Duration of DM (years) & $9.7 \pm 3.1$ & & \\
\hline
\end{tabular}

\section{TABLE 1: Sociodemographic and participant characteristics}

DM: diabetes mellitus; BMI: body mass index

The patients' history of diabetes-related morbidities recording the patient's intake of insulin was also recorded. Retinopathy showed the highest microvascular complication (21.0\% (101/482)). Cardiovascular prevalence was high in the sample with $28.4 \%$ (137/482) reported cardiovascular diseases. Hypertension is the most common diabetic-related comorbidity (366 (75.9\%)). Insulin intake was reported by 18.9\% (91/482). The patients' history of diabetes-related morbidities is summarized in Table 2. 


\section{Cureus}

\begin{tabular}{|c|c|c|}
\hline & Description & Frequency $(\%)$ \\
\hline \multirow[t]{3}{*}{ Microvascular complications } & Retinopathy & $101(21.0)$ \\
\hline & Neuropathy & $59(12.2)$ \\
\hline & Nephropathy & $16(3.3)$ \\
\hline \multirow[t]{3}{*}{ Macrovascular complications and comorbidities } & $\mathrm{CVD}^{\mathrm{x}}$ & $137(28.4)$ \\
\hline & Hypertension & 366 (75.9) \\
\hline & Hyperlipidemia & $194(40.2)$ \\
\hline Insulin intake & Yes & $91(18.9)$ \\
\hline
\end{tabular}

\section{TABLE 2: Patients' history of diabetes-related morbidities}

* CVD: cardiovascular disease

Central tendency measures and reliability of the SF-36 scales are presented in Table 3. Concerning reliability, all scales meet the recommended $>0.70$ internal consistency criterion. The eight subscale scores range from 46.2 for $\mathrm{GH}$ to 82.4 for SF.

\begin{tabular}{|c|c|c|c|c|}
\hline Scales & Mean \pm SD & $95 \% \mathrm{Cl}$ & Median & Reliability \\
\hline Physical Functioning & $61.6 \pm(26.8)$ & $59.2-64.0$ & 68.0 & 0.89 \\
\hline Role Physical & $59.8 \pm(48.3)$ & $55.5-64.1$ & 75.0 & 0.93 \\
\hline Bodily Pain & $67.2 \pm(28.5)$ & $64.7-69.7$ & 82.0 & 0.91 \\
\hline General Health & $46.2 \pm(26.7)$ & $43.8-48.6$ & 48.0 & 0.81 \\
\hline Vitality & $61.3(32.8)$ & $58.4-64.2$ & 65.0 & 0.84 \\
\hline Social Functioning & $82.4(26.9)$ & $80.0-84.0$ & 90.5 & 0.96 \\
\hline Role Emotional & 73.0 (39.6) & $69.5-76.5$ & 100.0 & 0.91 \\
\hline Mental Health & $54.4(30.1)$ & $51.7-57.1$ & 60.5 & 0.82 \\
\hline
\end{tabular}

TABLE 3: Central tendency measures and reliability of the SF-36 subscales

\section{Regression analysis}

HRQoL determinants are investigated using multivariate regression. All sociodemographic and diabetesrelated disease variables are included in the full model. The best model is selected using AIC as indicated previously in the methodology section. Table 4 shows the results of the regression analysis. The models for the SF-36 (Table 4) showed that sex (female) had a negative effect across all sections in the SF-36. Other sociodemographic factors were significant predictors for certain SF-36 subscale scores, aging was associated with lower physical functioning $(\mathrm{PF})$, bodily pain $(\mathrm{BP})$, and role emotional (RE) scores $(\mathrm{P}<0.01)$, being married with higher general health (GH), vitality $(\mathrm{VT})$, and mental health $(\mathrm{MH})(\mathrm{P}<0.05)$, higher education with less VT $(\mathrm{P}<0.05)$ and being employed with worse GH $(\mathrm{P}<0.01)$ and higher $\mathrm{BP}$ and $\mathrm{MH}(\mathrm{P}<0.05)$. The association with diabetes-specific factors, microvascular complications, and diabetes duration were the most influential on HRQoL, each factor associates negatively and statistically significantly with five and four SF36 subscales, respectively. The PF construct shows the highest influence of the factors investigated. This is mainly reflected by the variance explained, that is, $41 \%$. The rest of the subscales, the models explained the portions of variance ranging between $9 \%$ and $34 \%$. 


\section{Cureus}

\begin{tabular}{|c|c|c|c|c|c|c|c|c|}
\hline & $\mathrm{PF}$ & RP & BP & GH & VT & SF & RE & MH \\
\hline \multirow[t]{2}{*}{ Constant } & 140.6 & 86.2 & 101.3 & 24.8 & 64.9 & 98.4 & 122.4 & 46.9 \\
\hline & $(p<0.001)$ & $(p<0.001)$ & $(p<0.001)$ & $(p=0.024)$ & $(p<0.001)$ & $(p<0.001)$ & $(p<0.001)$ & $(p<0.001)$ \\
\hline \multirow[t]{2}{*}{ Age (per year) } & -1.2 & & -0.6 & & & & -1.1 & \\
\hline & $(p<0.001)$ & & $(p=0.028)$ & & & & $(p=0.018)$ & \\
\hline \multirow[t]{2}{*}{ Female } & -21.3 & -24.6 & -18.2 & -9.0 & -14.7 & -23.9 & -31.5 & -16.6 \\
\hline & $(p<0.001)$ & $(p<0.001)$ & $(p<0.001)$ & $(p<0.001)$ & $(p<0.001)$ & $(p<0.001)$ & $(p<0.001)$ & $(p<0.001)$ \\
\hline \multirow[t]{2}{*}{ Married } & & & & 1.5 & 11.3 & & & 1.6 \\
\hline & & & & $(p<0.001)$ & $(p<0.001)$ & & & $(p=0.048)$ \\
\hline \multirow[t]{2}{*}{ College or nigner } & & & & & 3.8 & & & \\
\hline & & & & & $(p<0.001)$ & & & \\
\hline Employed & & & 3.8 & -11.3 & & & & 6.6 \\
\hline \multirow[t]{2}{*}{ BMI per $\mathrm{kg} / \mathrm{m} 2$} & -1.8 & & $(p=0.031)$ & $(p<0.001)$ & & & & $(p<0.001)$ \\
\hline & $(p<0.001)$ & & & & & & & \\
\hline Microvascular & -20.3 & & & -19.1 & & -17.4 & -13.5 & -14.2 \\
\hline Complications & $(p<0.001)$ & & & $(p<0.001)$ & & $(p<0.001)$ & $(p=0.016)$ & $(p<0.001)$ \\
\hline Macrovascular & -18.5 & & & -5.7 & -9.1 & & & \\
\hline Complications & $(p<0.001)$ & & & $(p=0.036)$ & $(p=0.008)$ & & & \\
\hline \multirow[t]{2}{*}{ Hypertension } & & & & -8.2 & & & & -4.1 \\
\hline & & & & $(p=0.011)$ & & & & $(p=0.041)$ \\
\hline \multirow[t]{2}{*}{ Hyperlipidemia } & & & & & & & & -10.8 \\
\hline & & & & & & & & $(p=0.006)$ \\
\hline Duration of diabetes (per & -6.5 & & -0.9 & -0.4 & -0.8 & & & \\
\hline year) & $(p<0.014)$ & & $(p<0.001)$ & $(p=0.032)$ & $(p=0.009)$ & & & \\
\hline \multirow[t]{2}{*}{ Insulin intake } & & -8.2 & & -13.4 & -8.1 & & & -6.9 \\
\hline & & $(\mathrm{p}<0.013)$ & & $(p<0.001)$ & $(p<0.001)$ & & & $(\mathrm{p}<0.026)$ \\
\hline
\end{tabular}

\section{TABLE 4: Multivariate linear regression analysis for the SF-36 scales}

BMI: body mass index; PF: physical functioning; RP: role physical; BP: bodily pain; GH: general health; VT: vitality; SF: social functioning; RE: role emotional; $\mathrm{MH}$ : mental health

\section{Discussion}

In this work, we investigated HRQoL and the factors that may influence HRQoL in diabetic patients in Saudi Arabia in primary care settings.

Sociodemographic and diabetes-specific variables were included in the investigation tool. Our investigation confirmed the importance of several diabetes-specific variables as per the literature. Our investigation confirmed obesity (per unit increase in BMI) [14-22], comorbidities such as hypertension [21,23-24], and dyslipidemia [21,24-25], and micro- and macrovascular complications [14, 21,24]. The sociodemographic variables that influenced HRQoL are age $[14,21,26]$, gender $[14,21,26]$, marital status $[14,21,26]$, and higher education $[14,21,26]$. These variables showed a very interesting influence on HRQoL, especially the notable differences between males and females.

The multivariate regression analyses indicate that while sociodemographic variables can be important, specifically gender, diabetes-related variables are more important predictors of HRQoL. Females are overall 
influencing the subscales as an exception. Microvascular complications, disease duration, and comorbidities were the most profound predictors of a negative QoL. The combination of these variables seems to explain a large part of the variability in most subscales. Only RP shows resistance to the factors investigated. Only $9 \%$ of the variability in this subscale is explained. In contrast, because of the relationships observed in this study and previous studies, it is plausible to conclude that trying to avoid obesity, delaying the development of complications, hypertension, hyperlipidemia, and other non-diabetic comorbid conditions will enhance HRQoL. Such enhancement can lead to improved life expectancy as well. Unfortunately, the current practice overlooks the impact of the treatment and the complications' effect on the HRQoL in the prevention protocols. Such a gap between implemented treatments and prevention policies and the patient's HRQoL opens the door for questioning the extent of treatment satisfaction among patients [27]. The results of this study conform to the findings in several previous studies. The sociodemographic variables are major influences, specifically being a female patient on the HRQoL. This result was profound in our study. The high prevalence of some complications and comorbidities showed that diabetic-specific comorbidities are major influences.

\section{Limitations}

The study has several limitations. The cross-sectional design of the study only allows for the casual association, not causality. The single-center setting means that the results should be generalized cautiously. The low response rate among the older patients cast some doubts over some of the results due to the lack of representation of these older age groups. Finally, the study overlooked assessing the patients psychologically and such factors can be very detrimental in the patient's perception of HRQoL.

\section{Conclusions}

This study can be utilized in the practices of healthcare and medicine promotion in WHC specifically and in primary care settings in Riyadh city more generally. Improving HRQoL in diabetic patients requires an understanding of the factors that can influence it. Changes in the delivery of healthcare to be more personalized in diabetes to account for these factors may provide better results. We recommend (a) continuous measuring of HRQoL in diabetes to keep understanding the determinants of HRQoL in T2DM, (b) changes in healthcare provided to T2DM patients for more personalized medical care that can account for the disparities between individuals, and (c) educational and psychological support especially for female patients.

\section{Additional Information \\ Disclosures}

Human subjects: Consent was obtained by all participants in this study. Animal subjects: All authors have confirmed that this study did not involve animal subjects or tissue. Conflicts of interest: In compliance with the ICMJE uniform disclosure form, all authors declare the following: Payment/services info: All authors have declared that no financial support was received from any organization for the submitted work. Financial relationships: All authors have declared that they have no financial relationships at present or within the previous three years with any organizations that might have an interest in the submitted work. Other relationships: All authors have declared that there are no other relationships or activities that could appear to have influenced the submitted work.

\section{References}

1. van Dieren S, Beulens JW, van der Schouw YT, Grobbee DE, Neal B: The global burden of diabetes and its complications: an emerging pandemic. Eur J Cardiovasc Prev Rehabil. 2010, 17:3-8. 10.1097/01.hjr.0000368191.86614.5a

2. Dall TM, Zhang Y, Chen YJ, Quick WW, Yang WG, Fogli J: The economic burden of diabetes . Health Aff (Millwood). 2010, 29:297-303. 10.1377/hlthaff.2009.0155

3. Sherif S, Sumpio BE: Economic development and diabetes prevalence in MENA countries: Egypt and Saudi Arabia comparison. World J Diabetes. 2015, 6:304. 10.4239/wjd.v6.i2.304

4. Massi-Benedetti M: The cost of diabetes type II in Europe: the CODE-2 study . Diabetologia. 2002, 45:1-4.

5. Alberti KG, Gries FA: Management of non-insulin-dependent diabetes mellitus in Europe: a concensus view . Diabet Med. 1988, 5:275-281. 10.1111/j.1464-5491.1988.tb00984.x

6. American Diabetes Association: Standards of medical care in diabetes-2016 abridged for primary care providers. Clin Diabetes. 2016, 34:3-21. 10.2337/diaclin.34.1.3

7. Speight J, Reaney M, Barnard K: Not all roads lead to Rome-a review of quality of life measurement in adults with diabetes. Diabet Med. 2009, 26:315-327. 10.1111/j.1464-5491.2009.02682.x

8. Kiadaliri AA, Najafi B, Mirmalek-Sani M: Quality of life in people with diabetes: a systematic review of studies in Iran. J Diabetes Metab Disord. 2013, 12:54.

9. 36-item short form survey (SF-36). (2017). Accessed: January 18, 2017: https://www.rand.org/health/surveys_tools/mos/36-item-short-form.html.

10. Aghamollaei T, Eftekhar H, Shojaeizadeh D, Mohammad K, Nakhjavani M, Ghofrani Pour F: Behavior, metabolic control and health-related quality of life in diabetic patients at Bandar Abbas diabetic clinic. Iran J Public Health. 2003, 32:54-59.

11. Aghamolaei T, Eftekhar H, Mohammad K, Sobhani A, Shojaeizadeh D, Nakhjavani M, Ghofranipour G: Influence of educational intervention using interaction approach on behavior change, hemoglobin AlC and 
health-related quality of life in diabetic patient. Journal of School of Public Health and Institute of Public Health Research. 2005, 3:1-2.

12. Jacobson AM, De Groot M, Samson JA: The evaluation of two measures of quality of life in patients with type I and type II diabetes. Diabetes Care. 1994, 17:267-274. 10.2337/diacare.17.4.267

13. Glasgow RE, Ruggiero L, Eakin EG, Dryfoos J, Chobanian L: Quality of life and associated characteristics in a large national sample of adults with diabetes. Diabetes Care. 1997, 20:562-567.

14. Rubin RR, Peyrot M: Quality of life and diabetes. Diabetes Metab Res Rev. 1999, 15:205-218.

15. Verma SK, Luo N, Subramaniam M, Sum CF, Stahl D, Liow PH, Chong SA: Impact of depression on health related quality of life in patients with diabetes. Ann Acad Med Singapore. 2017, 39:913-917.

16. Naughton MJ, Yi-Frazier JP, Morgan TM, et al.: Longitudinal associations between sex, diabetes self-care, and health-related quality of life among youth with type 1 or type 2 diabetes mellitus. J Pediatr. 2014, 164:1376-1383. 10.1016/j.jpeds.2014.01.027

17. Rubin RR, Wadden TA, Bahnson JL, et al.: Impact of intensive lifestyle intervention on depression and health-related quality of life in type 2 diabetes: the Look AHEAD Trial. Diabetes Care. 2014, 37:1544-1553.

18. Cohen J: $\mathrm{F}$ tests of variance proportions in multiple regression/correlation analysis . Statistical Power Analysis for the Behavioral Sciences. Academic Press, 1977. 407-453.

19. Green SB: How many subjects does it take to do a regression analysis . Multivariate Behav Res. 1991, 26:499510.

20. Burnham KP, Anderson DR, Huyvaert KP: AIC model selection and multimodel inference in behavioral ecology: some background, observations, and comparisons. Behav Ecol Sociobiol. 2011, 65:23-35.

21. Papadopoulos AA, Kontodimopoulos N, Frydas A, Ikonomakis E, Niakas D: Predictors of health-related quality of life in type II diabetic patients in Greece. BMC Public Health. 2007, 7:186.

22. Hanninen J, Takala J, Keinanen-Kiukaanniemi S: Quality of life in NIDDM patients assessed with the SF-20 questionnaire. Diabetes research and clinical practice. 1998, 42:17-27.

23. Lloyd A, Sawyer W, Hopkinson P: Impact of long-term complications on quality of life in patients with type 2 diabetes not using insulin. Value Health. 2001, 4:392-400. 10.1046/j.1524-4733.2001.45029.x

24. Hart HE, Redekop WK, Berg M, Bilo HJG, Meyboom-de Jong B: Factors that predicted change in healthrelated quality of life were identified in a cohort of diabetes mellitus type 1 patients. J Clin Epidemiol. 2005, 58:1158-1164. 10.1016/j.jclinepi.2005.02.021

25. Thommasen HV, Zhang W: Impact of chronic disease on quality of life in the Bella Coola Valley . Rural Remote Health. 2006, 6:528.

26. Wandell PE: Quality of life of patients with diabetes mellitus. An overview of research in primary health care in the Nordic countries. Scand J Prim Health Care. 2005, 23:68-74. 10.1080/02813430510015296

27. Bradley C, Speight J: Patient perceptions of diabetes and diabetes therapy: assessing quality of life . Diabetes Metab Res Rev. 2002, 18:64-69. 10.1002/dmrr.279 